\title{
Normalized Noise Spectra of Aircraft Take-off and Landing Operations
}

\author{
J. Pons and J. S. Santiago \\ Instituto de Acústica, C.S.I.C., c/Serrano 144, 28006 Madrid, Spain
}

Summary: Normalized to $0 \mathrm{~dB}$ spectra of take-offs and landing operations in the vicinity of MadridBarajas airport have been calculated from in-situ measurement of aircraft operations, with the aim of having noise spectra to measure the acoustic insulation of buildings affected by the entrance in service of a new runway and provide, when necessary, supplementary acoustic insulation to achieve $L_{\text {eq day }}=35 \mathrm{dBA}$ and $\mathrm{L}_{\mathrm{eq} \text { night }}=30 \mathrm{dBA}$ inside the buildings.

\section{INTRODUCTION}

At Madrid-Barajas Airport a new runway has entered in service in November 1998, located to the NW of the two existing ones and parallel to one of them. In normal operating conditions of the Airport, that is to say, with northern winds, it will be the runway used for day take-offs. This fact implies a new configuration of flight paths, both for take-off and landing operations, and a new definition of the areas adjacent to the airport as regards the noise impact on the population.

An ad-hoc regulation regarding environmental impact states that the dwellings and socio-cultural and school buildings within the area covered by the isophones of $\mathrm{L}_{\mathrm{eq}}$ day $=65$ $\mathrm{dBA}$ and $\mathrm{L}_{\mathrm{eq}}$ night $=55 \mathrm{dBA}$, for the present and future situation in year 2010, have to be supplemented by the airport operator with an acoustic insulation to achieve an internal noise level of $\mathrm{L}_{\text {eq day }}=35 \mathrm{dBA}$ and $\mathrm{L}_{\text {eq night }}=30 \mathrm{dBA}$.

\section{MEASUREMENT PROCEDURE}

To determine the present acoustic insulation performance of the buildings that could be affected by the noise of the aircraft, it was decided to determine the acoustic spectra along different isophones, ranging from $\mathrm{L}_{\mathrm{eq}}=80 \mathrm{dBA}$ to $\mathrm{L}_{\mathrm{eq}}=55 \mathrm{dBA}$, in steps of $5 \mathrm{dBA}$, and at different distances from the airport. The isophones were calculated by means of the Integrated Noise Model, version 5.1 a, by the Airport Authority.

An array of six measurement stations was placed, in points as near as the accessibility permitted, the during 10 days at distances ranging from the head of the runways up to $12 \mathrm{~km}$ to the North (in the take-off direction), and up to $5 \mathrm{~km}$ from the threshold in the landing side of the airport. Each measurement station consisted in an outdoor type 1 microphone connected to a digital tape recorder with more than $80 \mathrm{~dB}$ of dynamic range. A radio link was used to start and stop the tape recordings, so that the six stations recorded simultaneously the same flight.

A total of 938 aircraft operations were measured, with a result of more than 5200 valid recordings, both for take-off and landing. 
During the measurement periods (the measurement campaign extended from mid March to mid April 1997) there was neither rain nor heavy winds that could affect the normal functioning of the airport.

\section{ANALYSIS OF THE RECORDINGS}

The recorded tapes were examined to discard recordings that were affected by noise sources other than the aircraft, such as industries, open air sand mines, vehicles or urban sources of noise. A total of 2750 recordings with a signal-to-noise ratio better than $15 \mathrm{~dB}$ were retained.

The recorded tapes were later frequency analyzed in the laboratory in $1 / 3$ octave bands to obtain the spectra of the different types of aircraft in the different flying situations, and the mean spectra of fly-overs corresponding to different isophones.

\section{RESULTS}

The noise spectra corresponding to the same type of aircraft during take-off or landing at the different distances were compared and a mean spectrum was obtained for each type. Also, a comparison was made for fly-overs at different distances from the airport, and the mean spectra for take-offs and landings were grouped according to the distance to the head of the runway, for the case of take-offs, and to the threshold for landings.

In Figures 1 and 2 are presented the resultant spectra.

As seen in the figures, for the case of take-off operations, the normalized spectra are very similar up to the frequency of $400 \mathrm{~Hz}$, with differences bigger than $2 \mathrm{~dB}$ only in the region of 2 to $4 \mathrm{kHz}$. For the case of landing operations, the characteristic "hiss" of the noise of the aircraft appears clearly marked in the spectrum for the Near Zone, as compared with the spectrum for the Far Zone.

\section{APPENDIX}

Aircraft types measured: AT 42, B 727, B 73 F, B 73 S, B 737, B 747, B 757, B 767, BA 46, CL 65, DC 9, DC 10, EA 31, EA 300, EA 320, EA 340, FK 10, FK 50, FK 70, G 2, L 101, MD 80, MD 90, TU 54.

\section{ACKNOLEDGEMENTS}

The authors wish to thank all the personnel of the Instituto de Acústica that intervened in the measurements and analysis of the data. 


\section{Take-off operations}

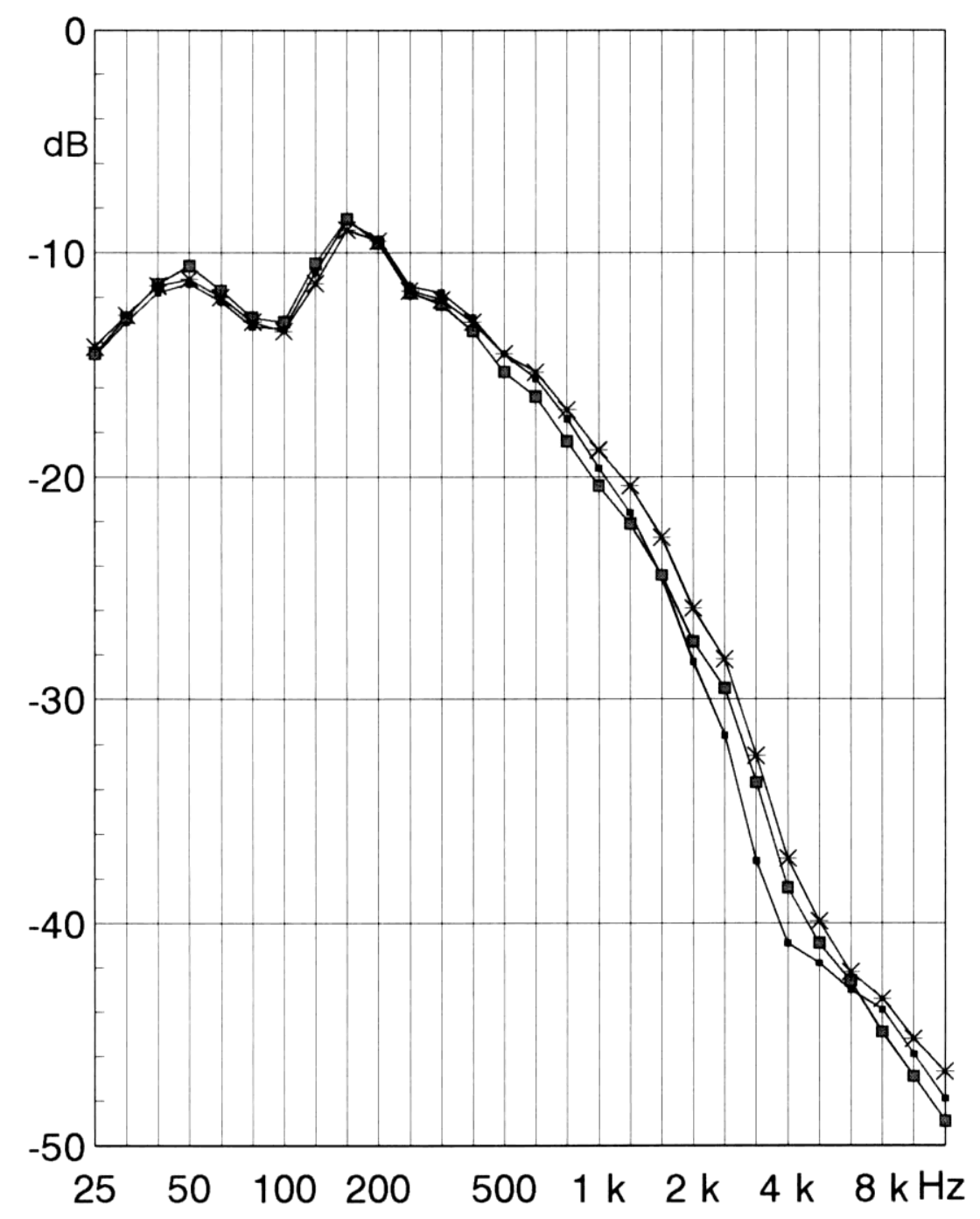

\section{* Near Zone $\rightarrow$ Intermediate Zone $\rightarrow$ Far Zone}

FIGURE 1: 0dB normalized spectra for take-off operations. Legend: Near Zone: up to $5.5 \mathrm{~km}$ from the head of the runway; Intermediate Zone: from $5.5 \mathrm{~km}$ up to $8 \mathrm{~km}$; Far Zone: more than $8 \mathrm{~km}$ from the head of the runway. 


\section{Landing operations}

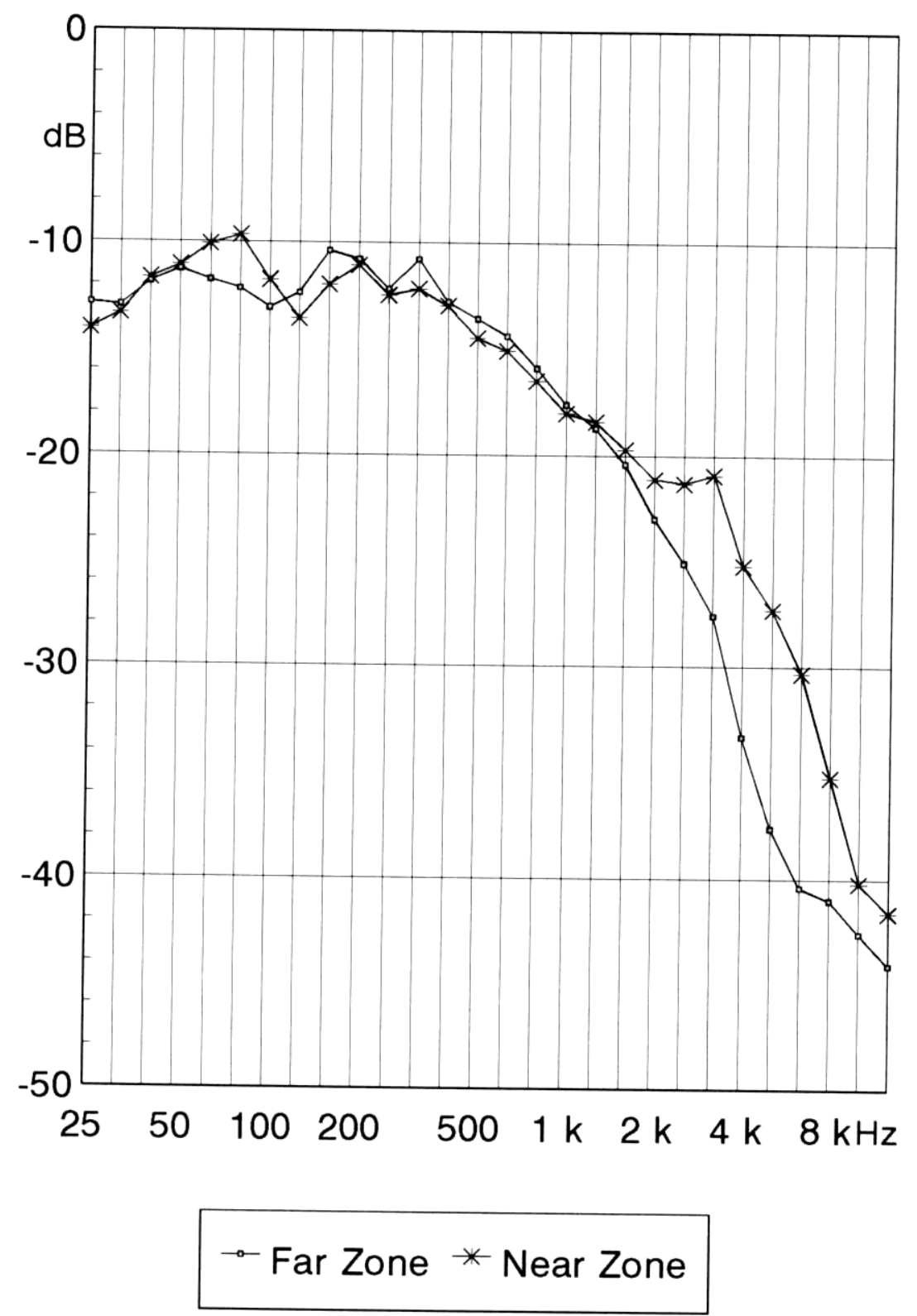

FIGURE 2: 0dB normalized spectra for landing. Legend: Near Zone: up to $2.5 \mathrm{~km}$ from the threshold of the runway; Far Zone: more than $2.5 \mathrm{~km}$ from the threshold of the runway. 